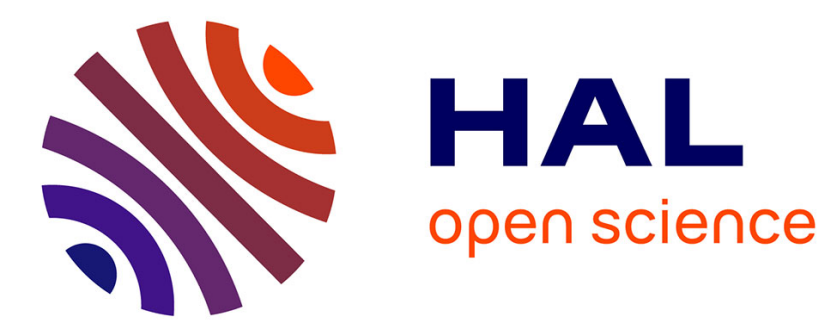

\title{
Challenges in expert user participation in design evaluation meetings
}

Romain Farel, Onur Hisarciklilar, Jean-François Boujut, Guillaume Thomann, François Villeneuve

\section{> To cite this version:}

Romain Farel, Onur Hisarciklilar, Jean-François Boujut, Guillaume Thomann, François Villeneuve. Challenges in expert user participation in design evaluation meetings. Journal of Design Research, 2013, 11 (2), pp.186-201. 10.1504/JDR.2013.055155 . hal-00856142

HAL Id: hal-00856142

\section{https://hal.science/hal-00856142}

Submitted on 30 Aug 2013

HAL is a multi-disciplinary open access archive for the deposit and dissemination of scientific research documents, whether they are published or not. The documents may come from teaching and research institutions in France or abroad, or from public or private research centers.
L'archive ouverte pluridisciplinaire $\mathbf{H A L}$, est destinée au dépôt et à la diffusion de documents scientifiques de niveau recherche, publiés ou non, émanant des établissements d'enseignement et de recherche français ou étrangers, des laboratoires publics ou privés. 


\title{
Challenges in expert user participation in design evaluation meetings
}

\author{
Romain Farel ${ }^{*}$ \\ Laboratoire Genie Industriel, \\ Ecole Centrale Paris, Grande Voie des Vignes, \\ Chatenay-Malabry, 92320, France \\ Fax: +33-1-41131272 \\ E-mail: romain.farel@ecp.fr \\ *Corresponding author

\section{Onur Hisarciklilar} \\ Department of Mechanical Engineering, \\ McGill University, \\ 817 Sherbrooke St. W, \\ Montreal, QC, Canada H3A 2K6 \\ E-mail: onur.hisarciklilar@mcgill.ca \\ Jean-François Boujut, Guillaume Thomann \\ and François Villeneuve \\ Grenoble-INP, UJF-Grenoble 1, CNRS, \\ G-SCOP UMR5272 Grenoble, F-38031, France \\ E-mail: jean-francois.boujut@grenoble-inp.fr \\ E-mail: guillaume.thomann@grenoble-inp.fr \\ E-mail: Francois.Villeneuve@g-scop.inpg.fr
}

\begin{abstract}
This paper explores the design collaboration between designers and expert users in the specific case of new surgical instrument design. To this end, two design evaluation meetings were studied. Decision and interaction analysis methods were applied to compare the effectiveness of the design team on discussing and solving design issues with and without active participation of the expert user. The observations showed that, in the absence of the user, the designers were unable to make decisions about technical solutions relating to usability issues, and the expert user's comments during the subsequent meeting significantly altered their decisions. These two observations indicate that the use of a support tool could have a significant role to help asynchronous communication in such a design process.
\end{abstract}

Keywords: collaborative design; annotation; surgical instrument; observation; evaluation; expert user; user integration; interaction analysis.

Reference to this paper should be made as follows: Farel, R., Hisarciklilar, O., Boujut, J-F., Thomann, G. and Villeneuve, F. (2013) 'Challenges in expert user participation in design evaluation meetings', J. Design Research, Vol. 11,

No. 2, pp.186-201. 


\section{Introduction}

Design of a product for users requires an active integration of the user during the whole design process. Design researchers studied this matter under several topics, for instance collaborative design, human-centred design or usability engineering (Hix and Hartson 1993; Nielsen 1993; Holtzblatt and Beyer 1998; Mayhew 1999; Battarbee and Koskinen 2005). ISO 13407 (1999) formalised and standardised a theory of user involvement, also known as UserCentred Design (UCD). User requirements, in contrast with design requirements, were given a particular attention (Samuel and Horrigan 1995; MacDonald 2001; Takala 2005) in design research.

In engineering design, the concept of collaboration between design actors was traditionally limited to communication between engineers. This point of view was changed in 90's when participatory experiments had shown a distinction in the designer and the user role. This reflected a critical shift in attitude: from designing for users to designing with users (Sanders 2002). This new concept was given several names, such as "user-design”, "post design" and "participatory design" (Carr-Chellman, Cuyar et al. 1998). Design processes that involve user participation have evolved differently according to profession, particularly in product and software engineering (Sanders 2002; Van der Voort and Tideman 2008).

In the vast literature of user-designer collaboration, most studies were performed on novices, engineering students or, at best, accessible users of relatively modest talents (Besnard and Bastien-Toniazzo 1999). In addition, only a few studies consider the influence of user integration in the design process where expert users are involved (for instance in medical applications), in spite of the direct relationship with the user in these cases (Xue, Yen et al. 2008). As an attempt to fill this gap, the concept of "real users as active partners" has been proposed by Kayis within the implementation of a collaborative design process in aerospace industry (Kayis et al, 2005). 
One important aspect of user integration is the design process is the design evaluation, particularly, when the product is going to be used in a complex usage situation. Typical examples of this type of products are pilot cockpits, air traffic control desks, professional sport equipments and surgical instruments. The common aspects that these products share can be characterised as: 1) User needs have an important tacit knowledge and experience to perform the task 2) The usage situation includes risky and critical moments that can lead to considerably hazardous consequences 3) Designer cannot be in the place of the user to simulate the real usage

These points clearly indicate that the design evaluation of products developed for "expert" users is significantly important, and deserves to be given a particular intention. In the research behind this paper, we have investigated the methodology of expert-user integration in the design process (Rasoulifar, Thomann et al. 2010). The present paper brings attention to the design evaluation phase, focuses on user-designer communication during evaluation meetings, and analyses the impact of this involvement on decision-making. The studied case is the design of an innovative surgical instrument for enabling a new type of spine operation that allows decreasing the incision size. A surgeon ${ }^{1}$ from Grenoble Hospital, France, was involved in the design process as the expert user. The design project took two years, during which several design and evaluation meetings were recorded. Two design situations pertaining to this case were selected for analysis: evaluation of the design by the engineering team (achieved through distant communication through a 3D annotation tool followed by a face-to-face meeting) and the subsequent face-to-face evaluation with the surgeon (the expert user). The interaction analysis method was used to analyse the interactive behaviour of the participants during distant communication sessions and face-to-face meetings. The decisions

\footnotetext{
${ }^{1}$ Head of the Orthopaedic and Traumatology Department, Michallon Hospital, Grenoble, France
} 
made in these two situations were then identified, analysed and compared to each other in order to highlight the effect of user involvement and validate its impact on the product.

The following section outlines the theoretical knowledge base of the paper through a review of literature on design activity analysis. Section three introduces the analysis method and the developed framework. Section four presents the case study. Section five then describes the analysis of the two design situations according to the developed framework, and explains the results. Finally, the last section discusses the limitations and future extensions to this study, and draws the conclusion.

\section{$2 \quad$ Studying design communication through activity analysis}

Meeting of participants with different stakes is crucial precisely because crossing intentions can create new insight and movement of thought and action (Buur and Larsen 2010). The 'designer-user' relation in design project touches on broad debates within contemporary participatory design and co-design communities and user-centred design research (Binder, Brandt et al. 2008; Heinemann, Landgrebe et al. 2012). In this context, activity analysis refers to a methodology aimed at understanding the behaviour and operating strategies of participants through processes and interactions with others in a given situation Garrigou (1995). This includes task analysis as a method to retrieve data, including a detailed description of both manual and mental activities. In this context an activity is considered as a set of tasks performed by a participant.

Design researchers have shown a very special interest in studying, describing and analysing activities in a design situation. "Activity analysis" appears in the title of more than 800 papers in design research journals. Lloyd and Scott (1994) collected protocols and imposed an external structure based on models of design. Akin and Lin (1995) proposed an activity-based model to analyse design protocols. Gero and Mc Neill (1998) developed and applied a number of methods to provide the basis for articulating different aspects of the 
behaviour of individual designers and for distinguishing between the design behaviours of different designers. In several publications, Cross and colleagues have proposed different aspects for analysing design activities. Most of these researchers refer to the Delft Workshop corpus (Cross, Christiaans et al. 1997), in which a video recording and transcriptions of a design session were given, and participants were asked to analyse the protocol. Besides faceto-face sessions, other types of meetings such as distant meetings have also aroused the interest of researchers (Ruiz-Dominguez and Boujut 2008).

This paper reports the observation and analysis of an expert user's participation in the design process of a surgical instrument. The interactions and the decision-making process in two different design evaluation meetings are analysed based on activity analysis approach. The particular analysis method applied is presented below.

\section{$3 \quad$ Methodology}

Design collaboration between designer and expert user is investigated through a four step methodology based on activity analysis:

(1) Definition of the interaction analysis framework, presented as follows in this section.

(2) Observation and recording of a design situation,

(3) Coding of the video corpus using the framework, and

(4) Analysis of the decision trends during the collaboration through coding results.

Section 4 presents the case study and how the observation and coding is undertaken. The result of the analysis is depicted in section five.

\subsection{Interaction analysis}

The interaction analysis applied in this paper is a conventional protocol analysis research method. It consists of first defining a classification framework for the relevant interactions, 
and then applying this framework to the transcribed corpus of the design meetings. Following these first two steps, the researcher can then study the trends and dynamics of the coded corpus. For this case study, the three steps applied are a) Framework selection, b) Coding, and c) Time-action analysis. These steps are detailed below.

\subsubsection{Framework selection}

The coding scheme depicts the list of interaction categories and their definition. The coding scheme developed for this study has two parts.

First, a list of interaction categories specific to design evaluation meetings was adopted. This is based on literature on cognitive ergonomics such as (Vacherand-Revel 2002) and (Robillard, D’Astous et al. 1998), and validated in (D’Astous, Détienne et al. 2004; Detienne, Boujut et al. 2004). While there are many studies on the analysis of design meetings, very few actually analyse the activities involved in evaluation meetings. The selected framework is shown Table 1.

Table 1. Design interaction categories (Coding scheme)

\begin{tabular}{|c|l|}
\cline { 2 - 3 } \multicolumn{1}{c|}{$\begin{array}{c}\text { Cognitive } \\
\text { synchronisation }\end{array}$} & $\begin{array}{l}\text { Ensuring that team members share a } \\
\text { common representation of a concept, } \\
\text { projects goals, constraints, design } \\
\text { strategy, solutions, etc. }\end{array}$ \\
\hline Argumentation & $\begin{array}{l}\text { Describing why a solution should or } \\
\text { shouldn't be adopted. }\end{array}$ \\
\hline $\begin{array}{c}\text { Assessment of } \\
\text { solution(s) }\end{array}$ & $\begin{array}{l}\text { Evaluating positively or negatively a } \\
\text { proposed solution }\end{array}$ \\
\hline $\begin{array}{c}\text { Assessment of } \\
\text { constraint(s) }\end{array}$ & $\begin{array}{l}\text { Evaluating positively or negatively a } \\
\text { constraint }\end{array}$ \\
\hline $\begin{array}{c}\text { Proposing } \\
\text { solution(s) }\end{array}$ & $\begin{array}{l}\text { Proposing, explaining a solution or an } \\
\text { alternative solution. }\end{array}$ \\
\hline $\begin{array}{c}\text { Enhancing a } \\
\text { solution }\end{array}$ & $\begin{array}{l}\text { Enunciating supplementary and } \\
\text { complementary ideas to develop a } \\
\text { solution }\end{array}$ \\
\hline
\end{tabular}


The second part of the coding scheme distinguishes between design interactions related to a technical aspect of the design (manufacturing methods, load calculations, etc.) and those relating to use of the surgical tool (Table 2). This distinction is necessary in order to identify the underlying intentions of the interactions and focus of participants in each interaction during evaluation meetings.

Table 2. Design interaction focus

\begin{tabular}{|c|l|}
\cline { 2 - 2 } \multicolumn{1}{c|}{$\begin{array}{c}\text { Technical } \\
\text { interaction }\end{array}$} & $\begin{array}{l}\text { Interacting concerning an aspect } \\
\text { related to the engineering knowledge } \\
\text { (mechanical, material, etc.) }\end{array}$ \\
\hline $\begin{array}{c}\text { Usage-related } \\
\text { interaction }\end{array}$ & $\begin{array}{l}\text { Interaction concerning the usage of } \\
\text { the product during the surgical } \\
\text { operation }\end{array}$ \\
\hline
\end{tabular}

\subsubsection{Coding}

The data corpus of communication comes from two sources: verbal discussions that occurred during the two aforementioned meetings (recorded in audio and video), and from an offline discussion software used by designers. The engineers performed the early distant discussion though an annotation tool previously developed by the authors (Hisarciklilar and Boujut 2009b). All interactions are coded using the following structure:

- The role of the participant in the project,

- The intent of the author (clarification, evaluation or proposition)

- The purpose of the textual content (a project requirement or problem-related constraint, a domain-specific constraint or the current solution)

The objective was to keep a trace of information exchanges in this format for further coding and analyses. 


\subsubsection{Time-action analysis}

The objective in this step is to determine the existing trends in the problem solving communication between the user and the designers. In other words, it consists of tracking the issues that were raised by design participants' discussions until they are resolved in evaluation meetings, order to highlight the differences in the way different parts of a decision are discussed and evaluated between the two meetings under study. The time-action analysis measures the time spent on a particular activity. The result of this analysis on the case study data is shown and discussed later in section 5 .

\section{4 - Introduction to the case study}

\subsection{A new operating-instrument for Spine surgery}

The design of the new instrument under study is for a novel application of a specific type of surgery called Minimally Invasive Surgery (MIS). MIS is a new kind of surgery in which the operation is performed through a small incision. Thanks to this smaller incision, the surgeon does not have to cut through muscles and only merely needs to separate them. This implies that the patient suffers from less pain and bleeding and recovers quicker. Despite the advantages for the patient, MIS operations are more difficult to perform for surgeons in comparison with the usual open-surgery techniques, and require special instruments. 

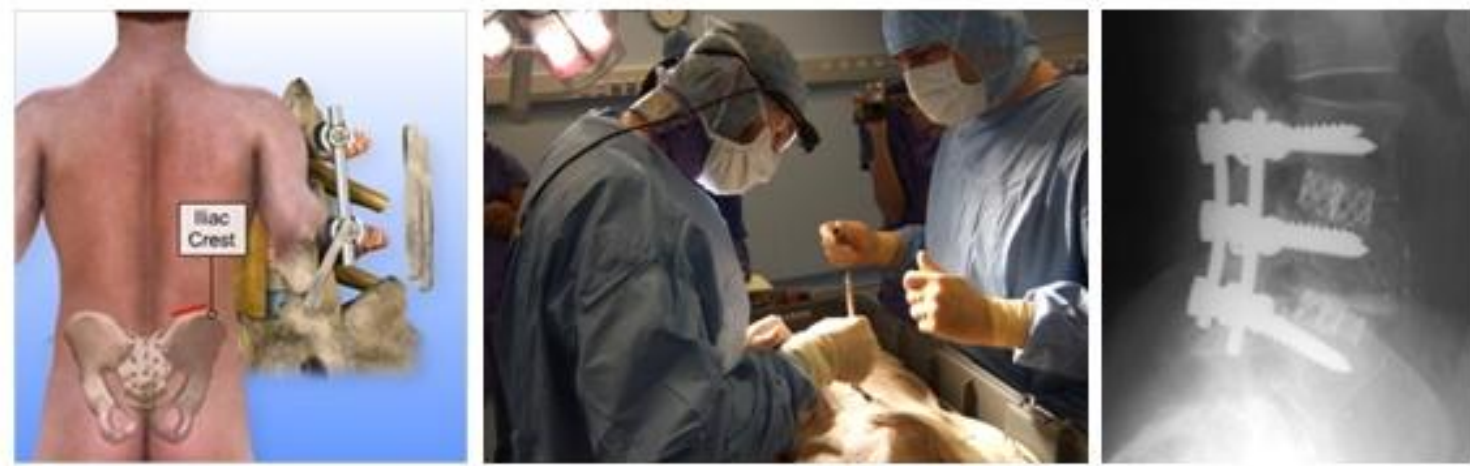

Figure 1. Left to right: Screw-Rod system on vertebra, emulation on cadaver, X-ray profile image on implanted system

The specific case studied here is an application of MIS in conventional spine surgery. The operation procedure consists of placing three pairs of screws and two implants (called rods) on three adjacent vertebras. The procedure normally requires a large incision $(12-15 \mathrm{~cm})$ to provide enough space for implementation (see Figure 1).

In the MIS procedure, the surgeon inserts the screws through small incisions using a tubular retractor and inserts the rods into the spine percutaneously. Unlike the open procedure, the surgeon has no direct access to or direct vision of the operating site. Consequently, the new procedure is more complex and requires specific instruments for inserting the screws and rods through the small incisions.

\subsection{The design evaluation}

The design project passed through different phases of discussion, ideation, 3D modelling, detail design, prototyping, and evaluation meetings. Although evaluation can be considered as a natural act after any design activity, each project has predefined moment for rather official evaluation and validation of the design object. In this study, argumentation that designers expressed before the meeting about the 3D model of the design object (surgical instrument) was captured in annotations. During the first evaluation meeting, these argumentations were considered and further discussed. At the end of the meeting, a statement that summarizes the 
discussions was added to each argumentation tree. Some of these statements proposed corrective actions while others pointed out a need to gather more data before the design decision can be made. These argumentations and statements were then rediscussed during the second meeting in the presence of the surgeon. The detailed analysis and the result of this analysis are shown and discussed later in section 5.

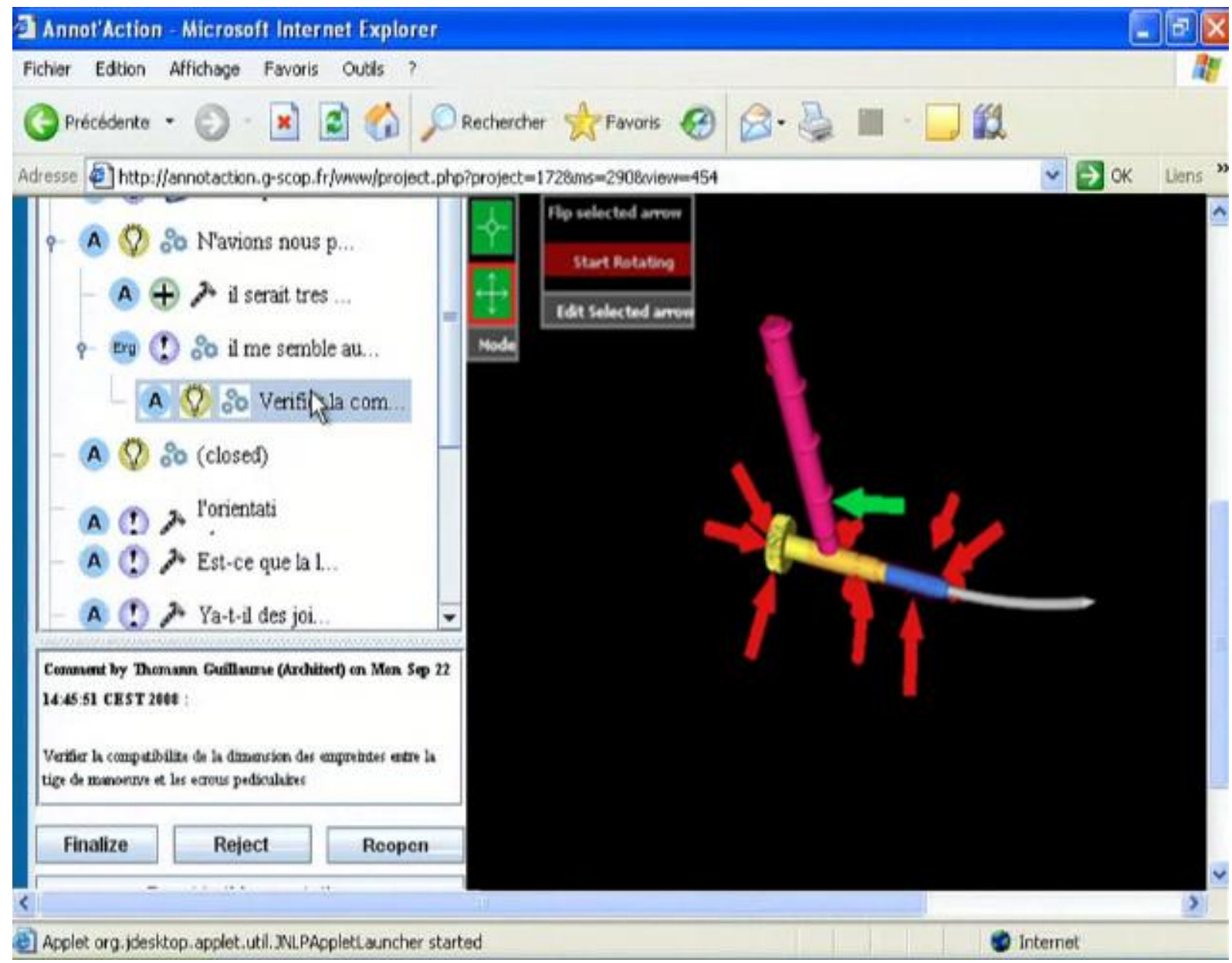

Figure 2. An example of an Annot'Action tool. Right side: Arrows pointing to the product model (as VRML object). Left side: Refers to the argumentation tree. Icons show the role, and the type of argumentation (e.g. proposition, question, etc.)

The recordings of the two meetings were coded, and data were extracted in the form of timeinteractions. Coding the interactions in these two meetings made it possible to highlight the proportion of interactions concerned with a given activity. It also helped to pinpoint the spread of focus between technical and use-related issues. The results of this analysis are shown in Figure 2. 
Table 3. Summary of two design meetings

\begin{tabular}{|l|l|l|}
\cline { 2 - 3 } \multicolumn{1}{c|}{} & \multicolumn{1}{c|}{ Participants } & \multicolumn{1}{c|}{ Agenda } \\
\hline Meeting 1 & Designers & $\begin{array}{l}\text { Technical evaluation, } \\
\text { solution proposition }\end{array}$ \\
\hline Meeting 2 & Designers + surgeon & Solution evaluation \\
\hline
\end{tabular}

The comparison of these two meetings shows that in both meetings the participants spent more than half the time on cognitive synchronization, shown in Figure 3. This ties in with a previous analysis undertaken using similar coding schemes (e.g. in (Ruiz-Dominguez and Boujut 2008)). In the second meeting, this type of interaction is even more frequent because the presence of the surgeon triggers question-and-answer type discussions concerning the use-related aspects.
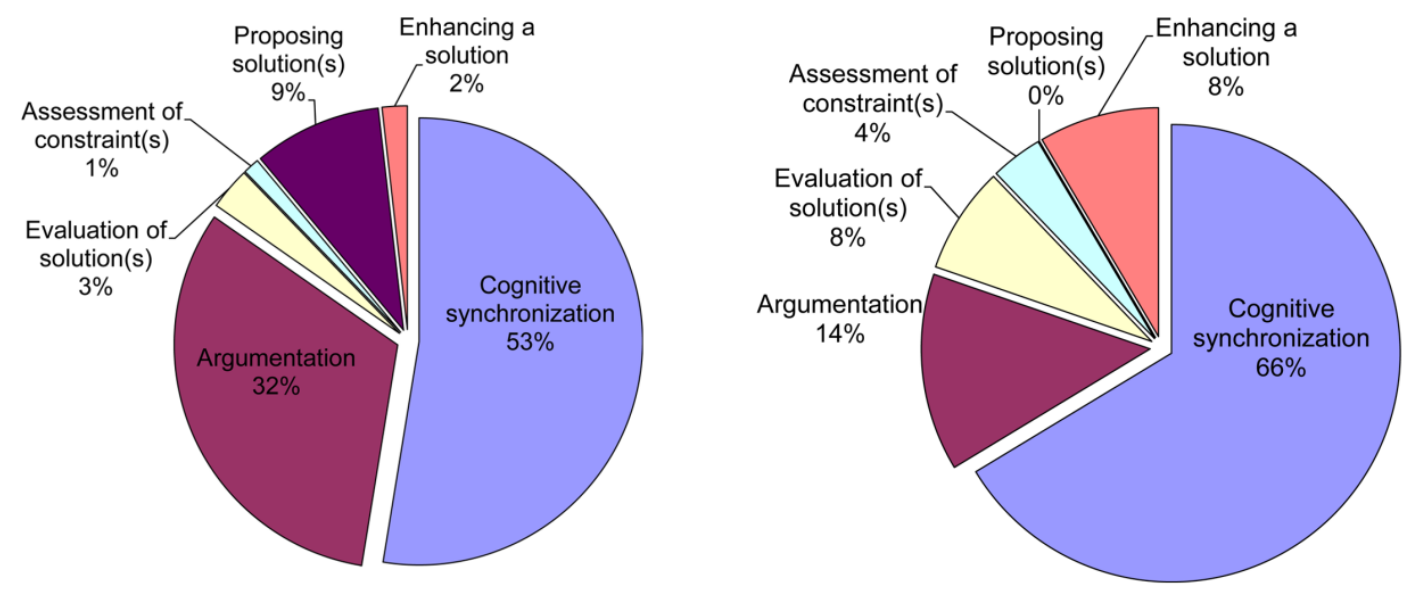

Figure 3. Design activity classification in evaluation meetings. a (left) First meeting, engineering design evaluation. $b$ (right) Second meeting, evaluation with user (surgeon)

A decrease in argumentation activity observed in the presence of the user is the result of two factors: many issues that the engineers discussed during the first meeting came up with 
an agreement before the second meeting. However, compared to the first meeting, the increase in activity concerned with enhancing the solution is notable. Finally, there were more direct evaluation interactions, since the second meeting primarily concerned assessment of existing solutions and requirements.

More interestingly, the results indicate a change in design activity orientation: the surgeon's participation leads to increased discussions about the use of the product rather than its technical aspects. Figure 3 shows the distribution of time spent on use versus technical aspects for each activity category. The left side of the graph shows the first meeting, and the right side the second one. Cognitive synchronization, argumentation and solution evaluation activities have almost the same focus distribution in both meetings. However, the share of use-related focus in solution evaluation is greater in the second meeting. In addition, the focus on use when requirements are being assessed is considerably greater compared with the first meeting. Finally, the time spent on technical issues during the solution assessment activity is quite high, which is in line with the objective of this meeting.

These results show that, although the overall profile of the interactions is similar in both meetings, the presence of the surgeon clearly provides the possibility for enhancing solutions from the point of view of use. The surgeon's presence also encourages the group to propose new solutions pertaining to the procedure.

A detailed analysis of the discussions and decisions within both meetings will be presented in the next section. The objectives are to reveal whether the importance of userelated interactions is linked to the importance of the surgeon's role, and to investigate the effect of the surgeon's participation on the discussions and decisions during the evaluation meeting more closely. 


\section{5 - Result: Analysis of design evaluation meetings}

As expected, the specific nature of this innovative product has shown the significant importance of expert user investment during design. Two evaluation meetings where the third prototype of the surgical instrument was examined were selected for the study. In the first meeting, the engineers evaluated the latest design solution. The second meeting was held with the participation of the surgeon in order to finalize the evaluation. Results of the analysis of these two meetings are presented in what follows.

This section presents the results of the two analyses on design activities and design decision undertaken by design actors.

\section{5-1 Analysis of design activities}

Using the activity category defined in the previous section (Table 1), recordings of the two meetings were coded, and data were extracted in the form of time-interactions. Coding the interactions in these two meetings made it possible to highlight the proportion of interactions concerned with a given activity. It also helped to pinpoint the spread of focus between technical and use-related issues.

Figure 4 shows the distribution of time spent on use versus technical aspects for each activity category. The left side of the graph shows the first meeting, and the right side the second one. As the figure shows, cognitive synchronization, argumentation and solution evaluation activities have almost the same focus distribution in both meetings. However, the share of use-related focus in solution evaluation is greater in the second meeting. In addition, the focus on use when requirements are being assessed is considerably greater compared with the first meeting. Finally, the time spent on technical issues during the solution assessment activity is quite high, which is in line with the objective of this meeting. 


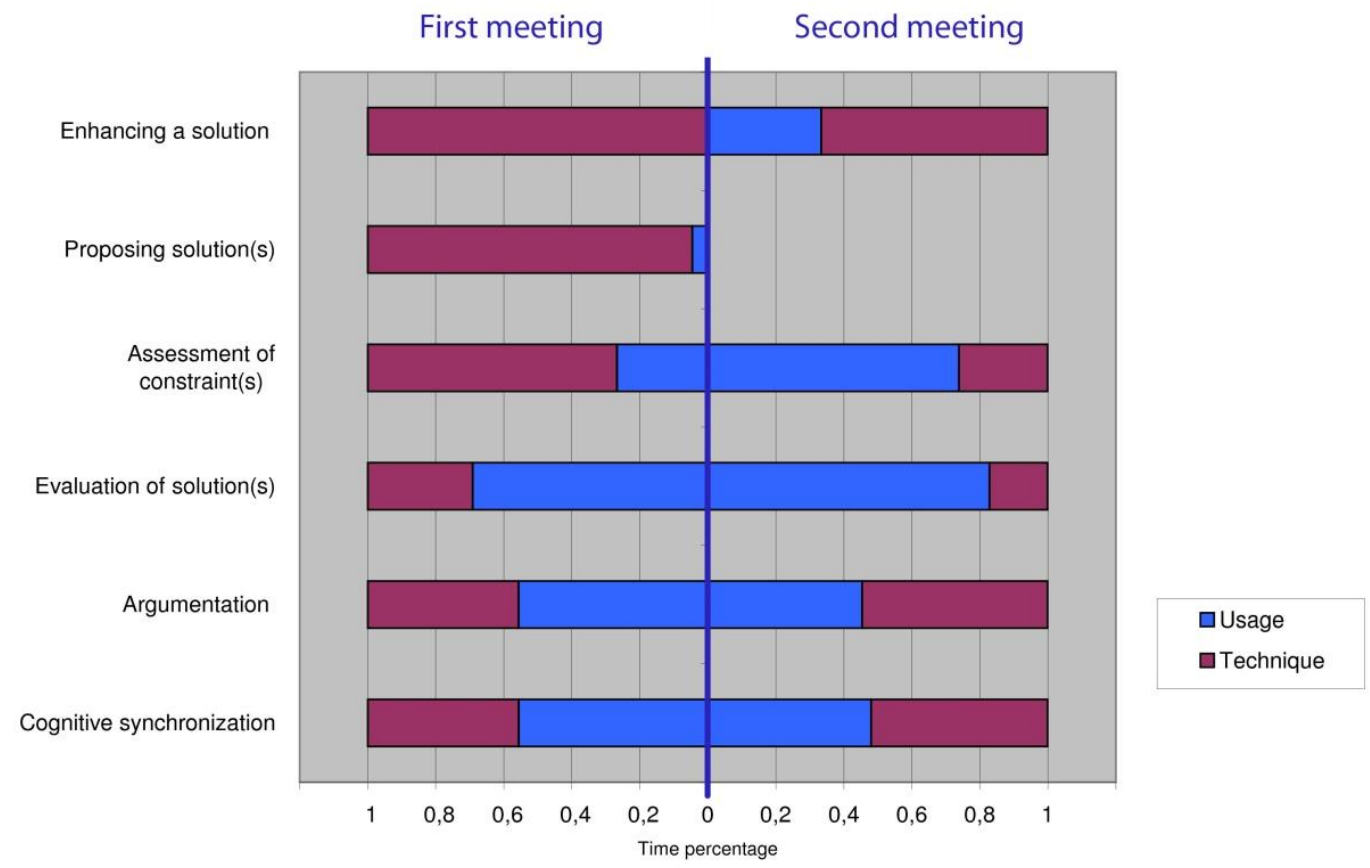

Figure 4. Comparison between design evaluation meetings, first without and second with the surgeon

The result of analysis shown in Figure 4 indicates a change in design activity orientation: the surgeon's participation leads to increased discussions about the use of the product rather than its technical aspects. These results show that, although the overall profile of the interactions is similar in both meetings, the presence of the surgeon provides the possibility for enhancing solutions from the point of view of use. The surgeon's presence also encourages the group to propose new solutions pertaining to the procedure.

\section{5-2 Analysis of the decisions in the two meetings}

In this experiment engineers used a software tool for pre-meeting distant discussions through annotating a digital mock-up of the surgical instruments. The first objective was to comment on the different design issues or raise new questions. Thanks to the relevant functionalities of the tool, the engineers were also able to respond to each other's comments. This asynchronous activity took place over the two-week period before the meeting. During the meeting, the engineers reviewed all of the issues raised about each part of the instrument and reached a 
series of final statements. These statements were added to the associated argumentation trees as final branches. Then, according to the decision made with regard to each statement, engineers progressively switched the status of the argumentation trees to rejected (the content of the annotation was not to be considered) or closed (the content was to be considered when elaborating the next version).

These statements fall into three categories: (1) finalised decisions where a corrective action or a design specification had been agreed on, (2) preliminary decisions for which an additional observation was needed (e.g. sterilisation procedure) in order to reach a finalised decision, and (3) non-decision statements due to a lack of expert knowledge. The statements are presented in Table 4 . Out of the 12 collective statements in this meeting, 6 were finalised (50\%), and the rest needed to be verified through use (25\%) and by the surgeon (25\%).

Table 4. The statements of design evaluation meeting

\begin{tabular}{|c|c|c|c|c|}
\hline & & $\begin{array}{c}\text { Finalised } \\
\text { Decisions (1) }\end{array}$ & $\begin{array}{l}\text { Need to be } \\
\text { verified vs } \\
\text { usage ( } 2 \text { ) }\end{array}$ & $\begin{array}{l}\text { No decision } \\
\text { Need for } \\
\text { surgeons } \\
\text { opinion (3) }\end{array}$ \\
\hline 1 & $\begin{array}{l}\text { Verifying the compatibility of the size } \\
\text { and form of the rod and screw nuts }\end{array}$ & & $\square$ & \\
\hline 2 & $\begin{array}{l}\text { Minimising the number of turns for rod } \\
\text { plug }\end{array}$ & $\square$ & & \\
\hline 3 & $\begin{array}{l}\text { Find compromise on rod smoothness, } \\
\text { between sterilisation and fabrication } \\
\text { costs }\end{array}$ & & $\square$ & \\
\hline 4 & $\begin{array}{l}\text { Handle orientation to be validated by } \\
\text { surgeon }\end{array}$ & & & $\square$ \\
\hline 5 & $\begin{array}{l}\text { Improving the contact site between the } \\
\text { rod and the grip }\end{array}$ & $\square$ & & \\
\hline 6 & Exterior diameter of the grip: $15 \mathrm{~mm}$ & $\nabla$ & & \\
\hline 7 & $\begin{array}{l}\text { Ask surgeon if he needs a support } \\
\text { system on the patient's back }\end{array}$ & & & $\square$ \\
\hline 8 & Prepare two grips: round and Allen & & $\square$ & \\
\hline 9 & $\begin{array}{l}\text { Using sodden Stainless steel (Material) } \\
\text { for long life cycle }\end{array}$ & 口 & & \\
\hline 10 & Exterior diameter of grip's body: 7,52 & $\nabla$ & & \\
\hline 11 & $\begin{array}{l}\text { Add a groove of } 0.2 \mathrm{~mm} \text {, inside, verify } \\
\text { with sterilisation process }\end{array}$ & & & $\square$ \\
\hline
\end{tabular}




\begin{tabular}{|l|l|l|l|l|}
\hline 12 & $\begin{array}{l}\text { Increase the interior diameter up to } \\
\text { cover empty space and verify to be } \\
\text { compatible with connecting part }\end{array}$ & $\square$ & & \\
\hline
\end{tabular}

When the scope of these issues is considered, it can be seen that although a higher number of issues discussed during this meeting were not related to use (but were instead more related to mechanical or manufacturing requirements), $40 \%$ of the statements were directly related to the use of the product.

When addressing a use-related issue, the participants followed three successive strategies. They first tried to consider previous user feedback based on a similar case. A decision was made when the participants were convinced of the compatibility between prior feedback and the issue at stake. When this strategy failed to bring participants to a decision, they tried to elaborate a use hypothesis by putting themselves in the user's place. A decision was made based on the hypothesis when this proved to work for the participants. When this strategy also failed, the participants decided to not to take any action before obtaining feedback from the user. The distribution of discussions is illustrated in Figure 5.
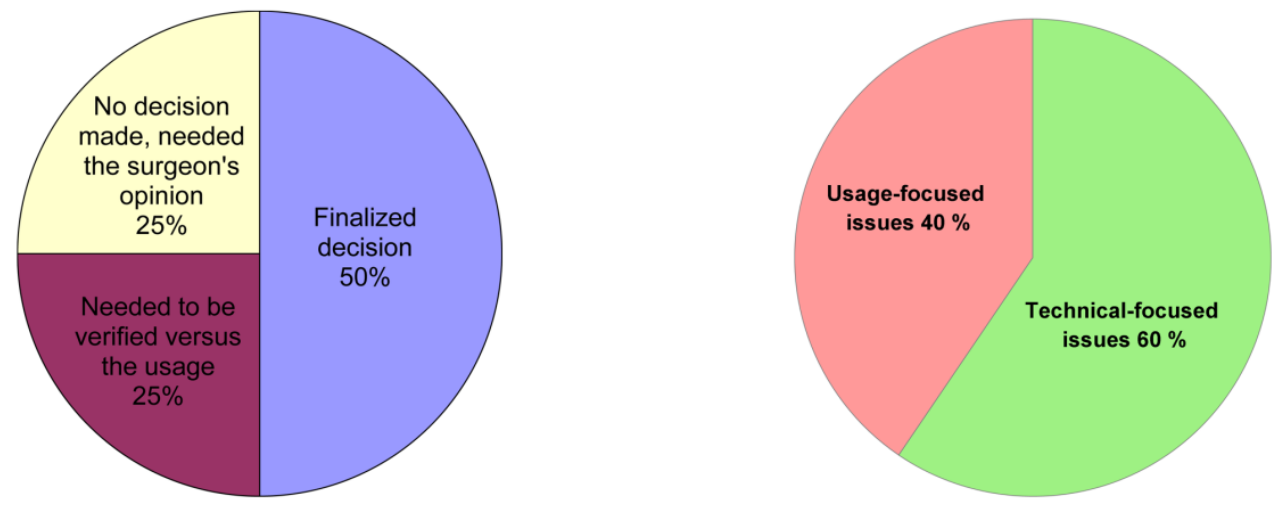

Figure 5. (a, left) Design evaluation meeting discussion distribution, (b, right) Use focus and technical focus of interactions

The data showed that although the objective of the meeting was to validate technical issues relating to the solution, the designers also had to consider a large number of usability- 
related issues. In other words, usability problems were inevitably involved, even for the technical validation of the design solution.

Furthermore, in the absence of the surgeon, the engineers had serious problems with dealing with these issues. In two thirds of the cases, they had no satisfying amount of user feedback upon which to base their decision. For half of these cases, they were unable to develop satisfying use hypotheses and had to postpone the decision until they received the user's feedback.

The next step of the analysis concerns the decisions made during the second meeting to which the user attended. In this meeting, some of the finalised issues in the first meeting were rejected by the user. These even included technically critical issues, such as decision number 6 in Figure 6 (see the three categories of statements in the left-hand column). In the right-hand columns, the status of each statement according to the discussions during the second meeting is given. 


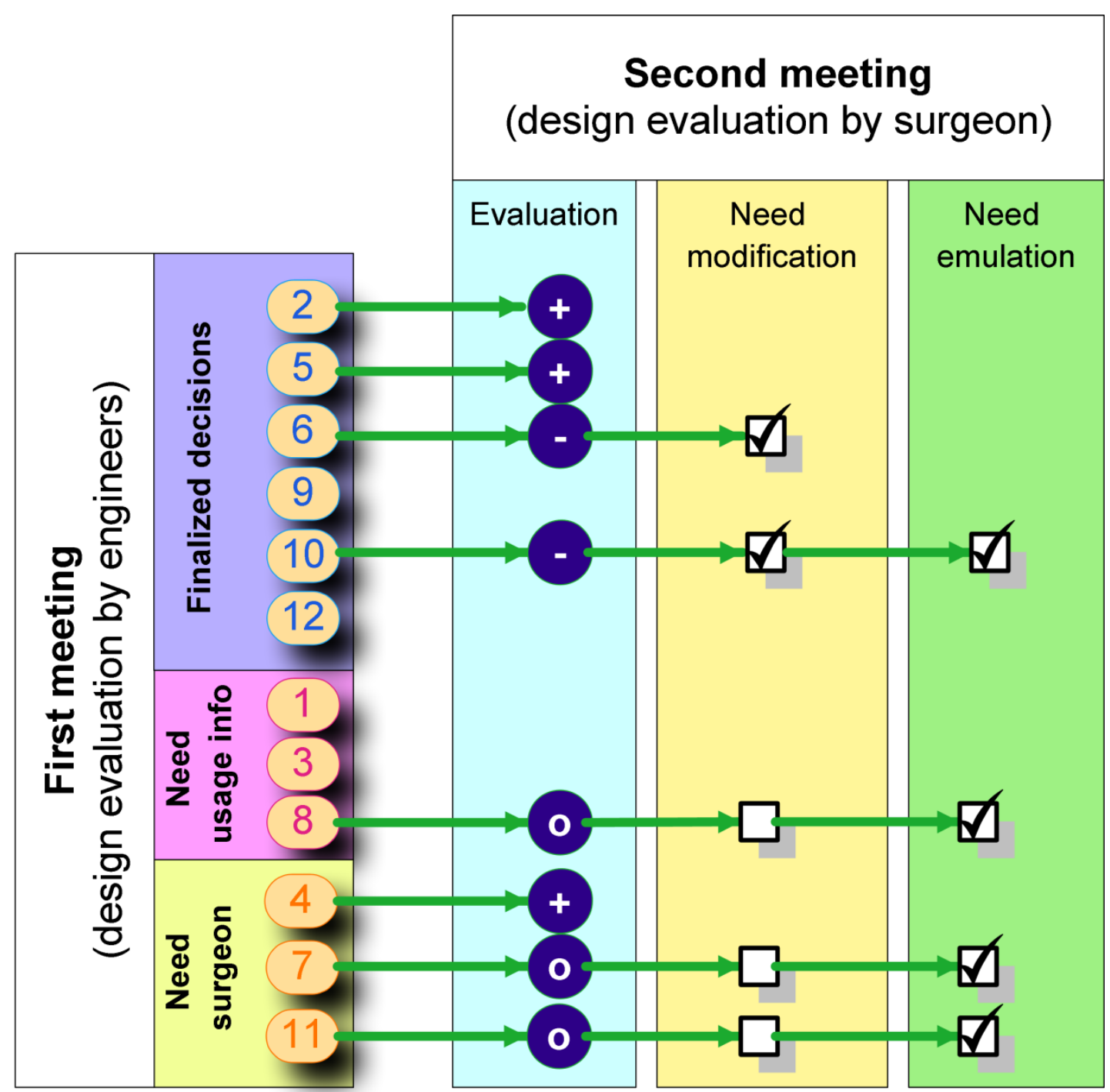

Figure 6. The status of the decisions made in the first meeting during the user evaluation meeting

Although the decisions belonging to the first category concern technical issues that were deemed to be finalised during the first meeting, two out of the four issues were not accepted by the user and needed rework. In half of the cases, clinical testing was required to clarify the decision making. These results show that some finalised decisions, even those related to technical issues, were questioned again by the user during the second meeting. As he assessed the solution, the user's specific expert point of view led to new insights for the designers. This demonstrates that such insight is missing during the first meeting. Therefore, the presence of the user is potentially beneficial for every type of design issue including technical questions. 
In short, the results presented in this section show that in the design of products such as surgical instruments, where the users are experts, the users' know-how plays an important role during the validation of both technical and use-related issues pertaining to the design solution.

\section{Conclusion}

Studying the design evaluation is an interesting and important research field. In the very specific domain of new product development for an expert user, the identification of the requirements cannot be performed in the initial stages of the design process. Instead they have to be gained progressively through the evolving steps of the design evaluation.

Through a case study, this paper demonstrated the analysis of design evaluation meeting. From an activity analysis viewpoint, this study proposed an improved framework of interactions, and validated the coding scheme through application. This analysis method was employed to analyse design interactions and decisions in a real design evaluation situation, that of a new surgical instrument. The case study provided an opportunity to observe and capture the designers' and the expert user's discussions, individually and in meetings, and use the coding technique to extract the data required. The analytical method is extendable and applicable to general evaluation meetings, in which communication and argumentation take place in the form of verbal discussions.

The premier result of this analysis for the design team was that the common understanding of the device's use (mentioned as cognitive synchronisation) was not granted, and in the absence of the expert user, the designers had significant difficulties to make concrete decisions. They were unable to acquire the knowledge needed to predict the way the product would be used. 
In second place, we observed that annotation is an effective method to encapsulate design discussions with product representations. Indeed, using annotation to promote communication in distributed design teams has been an active point of interest in design research? The case of design with expert user emphasizes the importance of user integration and the fact that he is not available for all meetings. In this regard, an adequate design communication tool with annotation capacity and simplicity is required.

Finally, the result of this study is limited by the restriction of one product design project, and the detail analysis of only two design evaluation meetings. The developed methodology and the analytical framework can be used for investigating the design evaluation of similar design situations.

In perspective, we chose two axis for further development: first, to apply the methodology to the other design project with expert user, surgical or other, to investigate the robustness of the analysis method. Second, the expert user's role seems to cover a wider range of specific users. For example, a project on design and manufacturing of assistive devices for disabled people to play music has begun 5 years ago (Thomann et al., 2008). Due to their handicap, communication with users is extremely difficult in this case. An adapted communication tool is therefore essential. With proper modifications and additional functionalities, the contribution of the present study would allow a better communication between users and designers during design process, particularly for design evaluation. 


\section{List of Tables}

Table 1. Summary of the two design meetings

Table 2. Design interaction categories (Coding scheme)

Table 3. Design interaction focus

Table 4. Design evaluation meeting statements extracted from Annot'action

********************************************************************************* $* * *$ 


\section{List of Figures}
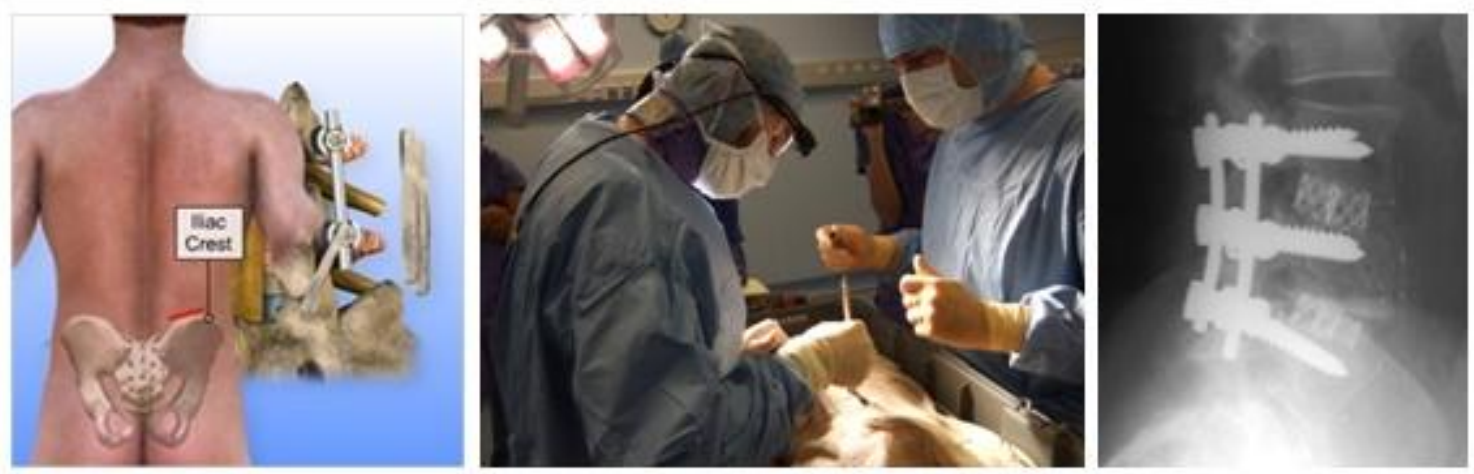

Figure 1. Left to right: Screw-Rod system on vertebra, emulation on cadaver, X-ray profile image on implanted system

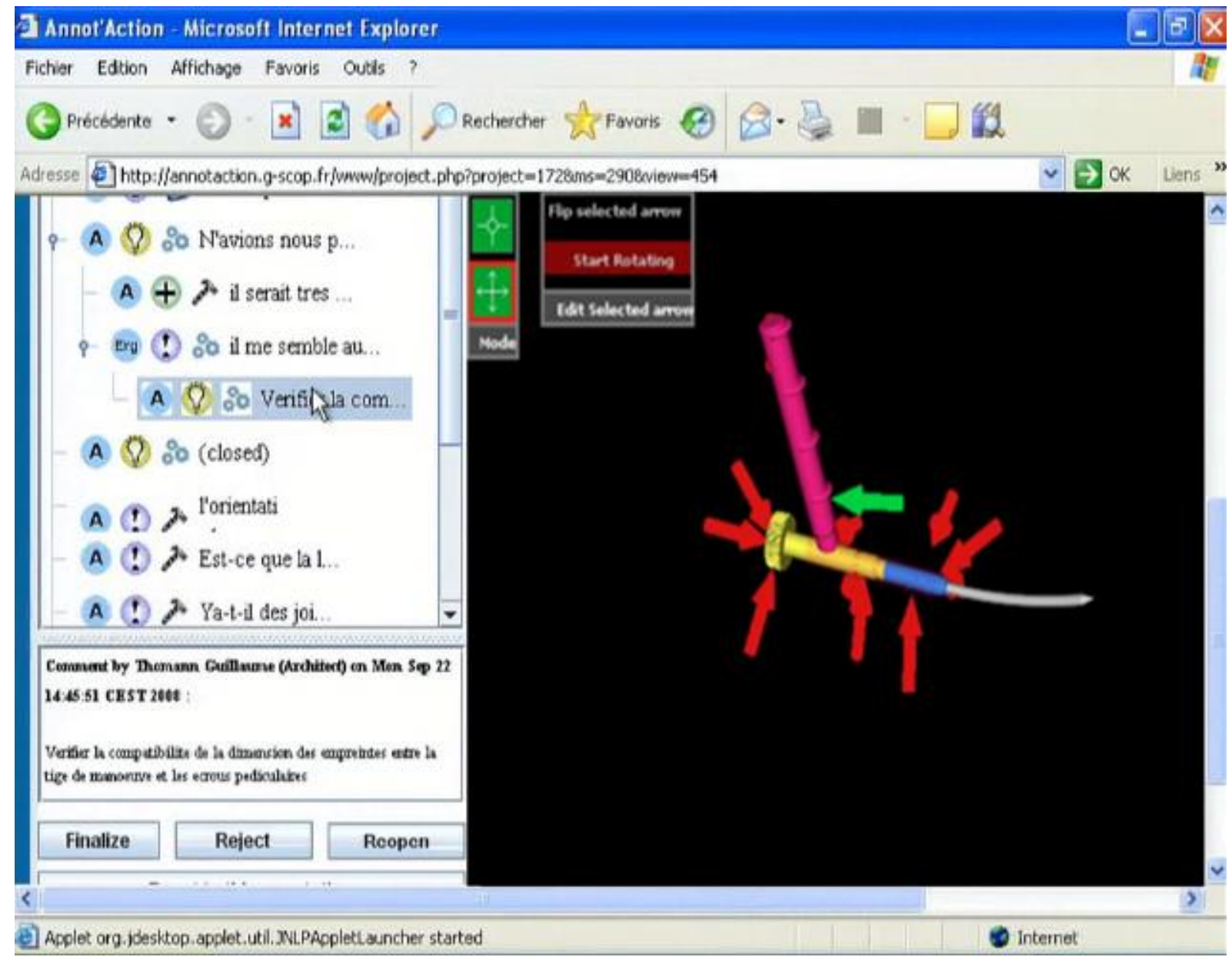

Figure 2. An example of an Annot'Action tool. Right side: Arrows pointing to the product model (as VRML object). Left side: Refers to the argumentation tree. Icons show the role, and the type of argumentation (e.g. proposition, question, etc.) 

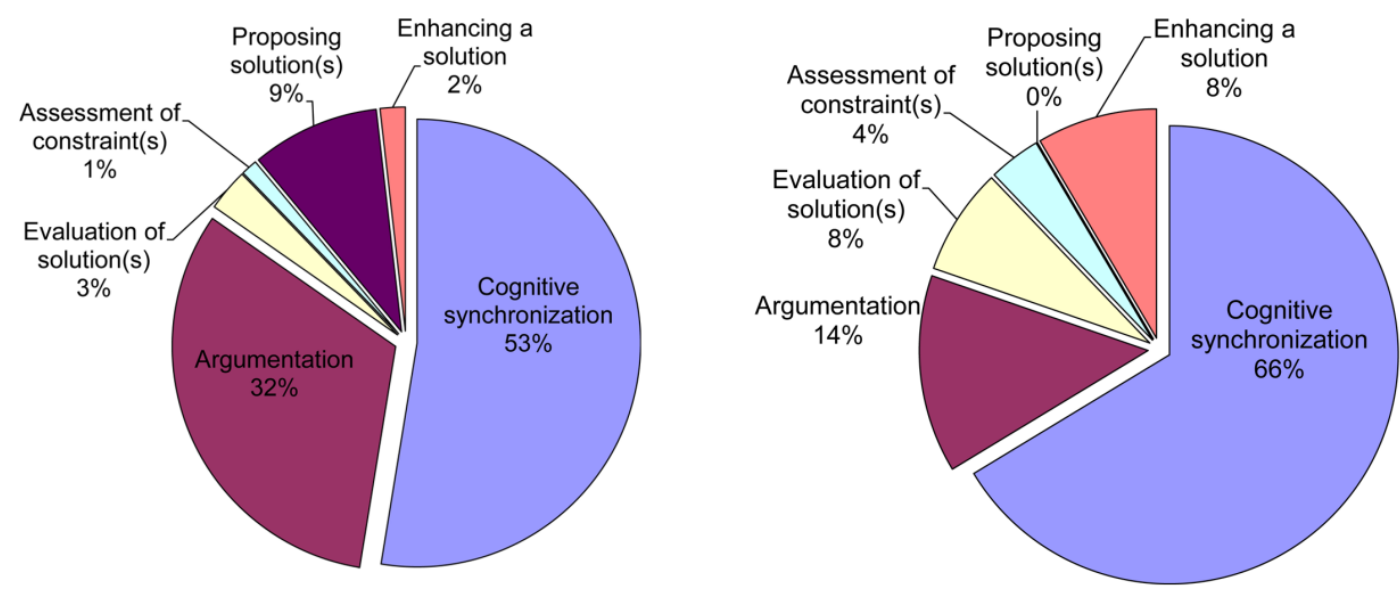

Figure 3. Design activity classification in evaluation meetings. a (left) First meeting, engineering design evaluation. $b$ (right) Second meeting, evaluation with user (surgeon)

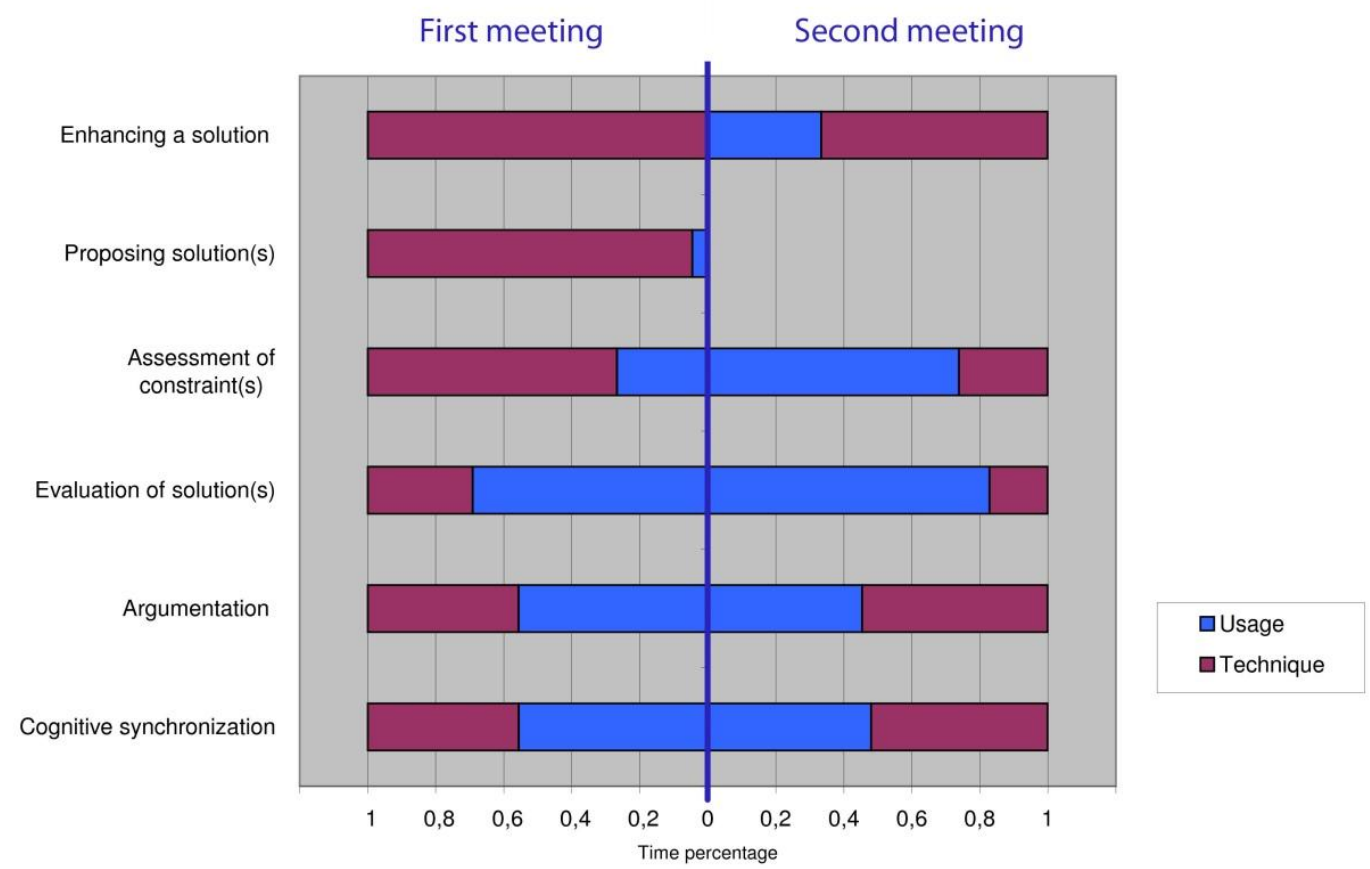

Figure 4. Comparison between design evaluation meetings, first without and second with the surgeon 

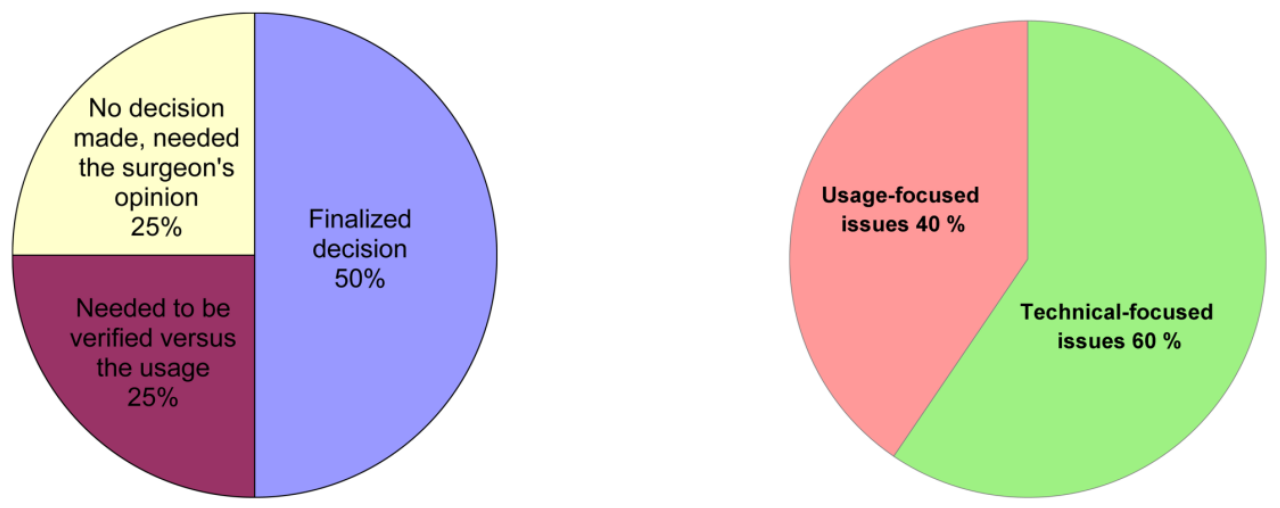

Figure 5. (a, left) Design evaluation meeting discussion distribution, (b, right) Use focus and technical focus of interactions 


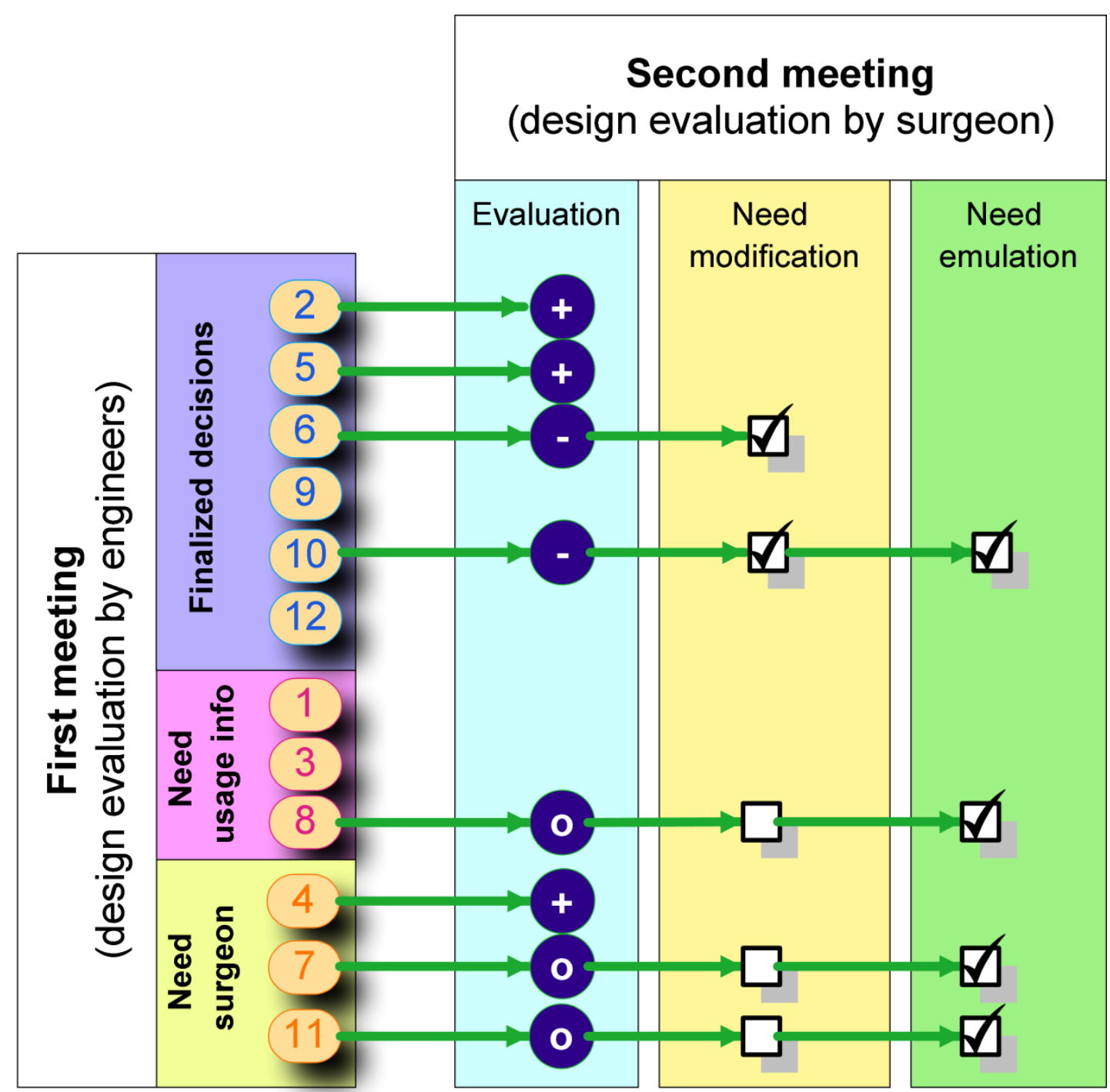

Figure 6. The status of the decisions made in the first meeting during the user evaluation meeting 


\section{References}

Akin, Ö. and C. Lin (1995). "Design protocol data and novel design decisions." Design Studies 16(2): 211-236.

Battarbee, K. and I. Koskinen (2005). "Co-experience: user experience as interaction." CoDesign 1(1): 5 - 18.

Besnard, D. and M. Bastien-Toniazzo (1999). "Expert error in trouble-shooting: An exploratory study in electronics." Int. J. Hum.-Comput. Stud. 50(5): 391-405.

Binder, T., E. Brandt, et al. (2008). "Design participation(-s) - a creative commons for ongoing change." CoDesign 4(2): 79-83.

Buur, J. and H. Larsen (2010). "The quality of conversations in participatory innovation." CoDesign 6(3): 121-138.

Carr-Chellman, A., C. Cuyar, et al. (1998). "User-Design: A Case Application in Health Care Training." Educational Technology Research and Development 46(4): 97-114.

Cross, N., H. Christiaans, et al. (1997). Analysing Design Activity, John Wiley.

D'Astous, P., F. Détienne, et al. (2004). "Changing our view on design evaluation meetings methodology: a study of software technical review meetings." Design Studies 25(6): 625-655.

Detienne, F., J. F. Boujut, et al. (2004). Characterization of Collaborative Design and Interaction Management Activities in a Distant Engineering Design Situation. Cooperative systems design. R. D. F. Darses, C. Simone, M. Zacklad, IOS Press: 8398.

Garrigou, A., F. Daniellou, et al. (1995). "Activity analysis in participatory design and analysis of participatory design activity." International Journal of Industrial Ergonomics 15(5): 311-327.

Gero, J. S. and T. Mc Neill (1998). "An approach to the analysis of design protocols." Design Studies 19(1): 21-61.

Heinemann, T., J. Landgrebe, et al. (2012). "Collaborating to restrict: a conversation analytic perspective on collaboration in design." CoDesign 8(4): 200-214.

Hix, D. and H. R. Hartson (1993). Developing User Interfaces: Ensuring Usability through Product and Process. New York, NY, Wiley.

Holtzblatt, K. and H. Beyer (1998). Contextual Design: Defining Customer-Centered Systems. Morgan Kaufmann Publishers, San Francisco.

ISO13407 (1999). Human-centred Design Processes for Interactive Systems. International Organization for Standardization. Genève, Switzerland.

Lloyd, P. and P. Scott (1994). "Discovering the design problem." Design Studies 15(2): 125140.

MacDonald, A. S. (2001). "Aesthetic intelligence: optimizing user-centred design." Journal of Engineering Design 12(1): 37 - 45.

Mayhew, D. J. (1999). The Usability Engineering Lifecycle: A Practitioner's Handbook for User Interface Design. San Francisco, CA, Morgan Kaufmann.

Nielsen, J. (1993). Usability Engineering, Academic Press Limited.

Rasoulifar, R., G. Thomann, et al. (2010). "Expert user-centred design, a cooperative product development approach." Asian International Journal of Science and Technology in Production and Manufacturing Engineering 3(2): 37-47.

Robillard, P. N., P. D'Astous, et al. (1998). Measuring cognitive activities in software engineering. The 20th International Conference on Software Engineering (ICES98), Kyoto. 
Ruiz-Dominguez, G. A. and J.-F. Boujut (2008). "A study of cognitive synchronisation in distant mediated design through design artefacts." J. of Design Research 7(2): 136154.

Samuel, A. and D. Horrigan (1995). "Engineering Design with a 'User-fluent' Finite Element Package: MECHANICA/Applied Structure." Journal of Engineering Design 6(1): 57 68.

Sanders, E. B.-N. (2002). From user-centered to participatory design approaches. Design and the social sciences: Making connections. J. Frascara. New York, Taylor \& Francis: 18.

Takala, R. (2005). "Product demonstrator: a system for up-front testing of user-related product features." Journal of Engineering Design 16(3): 329 - 336.

Vacherand-Revel, J. (2002). Les registres d'activités du travail coopératif médiatisé et distant de coconception de documents scientifiques. Communication en situation de travail à distance. Collection : Langage, cognition, interaction. E. Engrand, S. Lambolez and A. Trognon. Nancy, Presses Universitaires de Nancy.

Van der Voort, M. C. and M. Tideman (2008). "Combining scenarios and virtual reality into a new approach to including users in product design processes

" J. of Design Research 7(4): 393 - 410.

Xue, L., C. C. Yen, et al. (2008). "The design evolution of medical devices: moving from object to user." J. of Design Research 7(4): 411-438. 